\title{
ANÁLISE DE CONTEÚDO: HERMENÊUTICA NA EDUCAÇÃO
}

Karina Augusta Limonta Vieira*

\section{RESUMO}

A análise de conteúdo hermenêutica é um mixed methods que alia os princípios da hermenêutica e da análise de conteúdo qualitativa. Esse artigo tem como objetivo apresentar a sua importância e como foi utilizado na área da educação. Para alcançar o objetivo, esse artigo pretende responder três questões: Em que constitui a análise de conteúdo hermenêutica? Qual a importância desse método para a educação? Como utilizar esse método na educação? Esse artigo tem como base teórica a análise de conteúdo hermenêutica como mixed methods. Para ilustrar esse método, são analisados artigos publicados no Brasil em antropologia da educação, cuja análise apresenta a área da educação conectada com a antropologia e com pesquisas empíricas em escolas. Os resultados mostram que a área da educação é determinada por princípios teóricos, metódicos e formativos da antropologia. A conclusão apresenta a necessidade de um método para a crítica e reflexão da educação.

Palavras-chave: Análise de Conteúdo. Hermenêutica. Educação. Método.

\begin{abstract}
The Hermeneutic Content Analysis is a mixed methods allying hermeneutic principles and qualitative content analysis. This paper aims to show the importance of method and how it was used in Education field. For achieving the aim, this paper answers three questions: what does Hermeneutic Content Analysis constitute? How is important Hermeneutic Content Analysis for Education field? How to apply that method in Education? This paper has as theoretical support the Hermeneutic Content Analysis as mixed methods from work. To illustrate that method, some published papers in Brazil are analyzed in Anthropology of Education field showing from analysis the Education field linked to Anthropology and

* Doutora em Educação Escolar pela Universidade Estadual Paulista (Unesp), Araraquara. Docente da

Universidade Livre de Berlim (F.U.B.), Berlim, Alemanha e Universidade do Estado de Minas Gerais (Uemg),
\end{abstract}

Passos - MG.

@rquivo Brasileiro de Educação, Belo Horizonte, v. 6, n. 13, jan-abr, 2018. 
empirical researches in schools. The results show Education field is established theoretical, methodical and formative principles of Anthropology. The conclusion shows necessity for method in order to criticize and to reflect on Education field.

Keywords: Content Analysis. Hermeneutic. Education. Method.

\section{INTRODUÇÃo}

A pesquisa em educação no Brasil tem se configurado como um campo em que há uma eminência de trabalhos publicados de abordagem qualitativa. Diante do interesse por abordagem qualitativa (ANDRÉ, 2013, WARDE, 1990), nas décadas de 70 e 80, advindo das críticas a respeito dos trabalhos quantitativos (BOGDAN; BIKLEN, 1982), hoje a pesquisa em educação é um campo que prioriza pesquisas qualitativas compostas de um universo heterogêneo de métodos e técnicas, que vão desde a análise de conteúdo com toda sua diversidade de propostas, passando pelos estudos de caso, pesquisa participante, etc. (GATTI, 1992, 2001; GATTI; ANDRÉ, 2013).

Nesse sentido, proponho apresentar nesse artigo um método inovador e atual para a pesquisa em educação, a análise de conteúdo hermenêutica. De origem alemã, esse método tem sido desenvolvido com uma perspectiva de aprofundar as análises em conteúdos educacionais; nos quais a interpretação, a compreensão e a reflexão sejam consideradas elementos fundamentais no processo de análise de um conteúdo da pesquisa educacional, pois possibilita encontrar elementos textuais dos artigos que passam despercebidos em uma mera análise descritiva (VIEIRA, 20161; VIEIRA; QUEIROZ, 2017; VIEIRA, 2017b).

A análise de conteúdo hermenêutica é um método que alia hermenêutica e análise de conteúdo qualitativa (VIEIRA, 2017b; BERGMAN, 2010). É também um método que favorece a interpretação, a compreensão e a reflexão da realidade educacional. Desse modo, é importante pensar em um método que amplie a análise de conteúdo descritiva. Eis que suscito as seguintes questões para esse artigo: Em que

\footnotetext{
${ }^{1}$ Essa pesquisa tem sua origem na tese "A construção do conhecimento em Antropologia da Educação: levantamento, análise e reflexão de artigos publicados no Brasil" apresentada no Programa de Pós-Graduação em Educação Escolar no ano de 2016.
}

@rquivo Brasileiro de Educação, Belo Horizonte, v. 6, n. 13, jan-abr, 2018. 
constitui a análise de conteúdo hermenêutica? Qual a importância desse método para a educação? Como utilizar esse método na educação?

Para responder a essas problemáticas, esse artigo tem como objetivo apresentar o método da análise de conteúdo hermenêutica, a sua importância para a educação e como foi utilizado na área da educação em análise de conteúdos. Esse artigo tem como base teórica a análise de conteúdo hermenêutica como mixed methods de Vieira (2016²) e Vieira e Queiroz (2017 a) em conjunto com os princípios hermenêuticos e hermenêuticos educacionais de Danner (2006), Rittelmeyer e Parmentier (2006) e os princípios da análise de conteúdo qualitativa de Schreier (2014).

A análise de conteúdo hermenêutica é constituída por um movimento circular de análise, interpretação e compreensão do conteúdo do texto, desse modo, envolve a hermenêutica e a análise de conteúdo qualitativa. A hermenêutica é a arte da interpretação de compreender o texto que ocorre num movimento circular que envolve tanto o lado objetivo, quanto o subjetivo. A análise de conteúdo qualitativa é um método para descrever sistematicamente o significado dos dados qualitativos, por meio de codificação e categorização e que contém todos os aspectos que caracterizam a descrição e a interpretação do material. A análise de conteúdo hermenêutica, que também pode ser definida como um mixed de métodos, segundo Vieira (2017a), em que consiste a hermenêutica e a análise de conteúdo qualitativa. Esse tipo de análise está constituído, então, de dois métodos regidos pela sistematização, codificação, categorização, interpretação, compreensão e reflexão.

\section{A ANÁLISE DE CONTEÚDO HERMENÊUTICA}

A análise de conteúdo hermenêutica é um mixed methods e, nesse momento, apresento a constituição desse método. É composto pela hermenêutica e análise de conteúdo qualitativa.

\subsection{Hermenêutica}

\footnotetext{
${ }^{2}$ Parte dessa pesquisa foi financiada pelo Conselho Nacional de Desenvolvimento Científico e Tecnológico e pelo Programa de Doutorado Sanduíche no Exterior - Processo BEX 7334/14-1 com estágio doutoral na Universidade Livre de Berlim/ Alemanha.
}

@rquivo Brasileiro de Educação, Belo Horizonte, v. 6, n. 13, jan-abr, 2018. 
A hermenêutica é um método alemão que possui alguns elementos em sua constituição, como, por exemplo, a arte de compreender e conceitos básicos da hermenêutica. 0 significado da hermenêutica é evidenciado para além da noção de interpretação de texto, na qual envolve conceitos como compreensão, espírito objetivo e o círculo hermenêutico. Por isso, a hermenêutica é arte da interpretação de compreender o texto que ocorre num movimento circular que envolve tanto o lado objetivo, quanto o subjetivo.

A Hermenêutica como a arte de compreender, segundo Gadamer (1998), representante da hermenêutica filosófica, a definição da investigação hermenêutica é reportada à origem da palavra grega ermeneuein, isto é, a arte manifesta, interpretada, explicada e exposta. Nesse sentido, a hermenêutica possui o mesmo significado de Hermes, o

mensageiro de Deus que transmite aos mortais sem proclame, sem nenhuma partilha, mas basicamente explica os mandamentos divinos. Isto se aplica basicamente ao significado de ermeneia, "a 'declaração de pensamentos' em que a própria frase é uma declaração ambígua e consiste em expressão, explicação, interpretação e tradução (DANNER, 2006, p. 34).

Originalmente, hermenêutica é a interpretação do sentido do texto, porém, devese chamar a atenção também para os esforços da compreensão, porque a interpretação do texto, também envolve a compreensão do seu autor e o entorno de seu histórico. Por isso, a hermenêutica é mais que uma arte da intepretação, é a "arte da interpretação" de compreender, afirma Danner (2006), que representa a habilidade e o conhecimento do desenvolvimento de uma habilidade, a hermeneutike techné. Frequentemente hermenêutica é restrita à interpretação de texto, no entanto, a compreensão do significado hermenêutico não se estende apenas aos textos. Mas também, reforça Rittelmeyer (2013), lida de maneira mais ampla com os fenômenos do mundo da vida, na medida em que nos apresenta incompreensíveis ou enigmáticos.

Os conceitos básicos da hermenêutica são: a compreensão, a responsabilidade da compreensão, o círculo hermenêutico e as regras da hermenêutica. Esses conceitos se complementam no decorrer da pesquisa hermenêutica e da interpretação e compreensão do texto. A compreensão é o principal conceito da hermenêutica. Nós 
somos capazes de compreender como outras pessoas falam uns com os outros, leem cartazes, ouvem música ou seguem uma palestra, assim como, compreendemos os gestos dos outros, as suas palavras, o convite da publicidade ou um contexto espiritual. Mas acontece que um gesto não é precisamente "compreendido", mas apenas "explicado" por meio dos movimentos corporais do braço e mão, da força muscular e do consumo de energia, explica Danner (2006).

Esse exemplo dado pelo autor consiste em explicitar a diferença existente entre explicar (erklären) e compreender (verstehen), porque muitas vezes o conceito de compreensão é confundido com explicação. Segundo Dilthey (apud Danner, 2006), compreensão não é um processo imediato, irrefletido, como a explicação, mas deve ser refletida em sua estrutura, no seu desempenho, e na sua complexidade. É um processo de reflexão, e não uma forma imediata. A distinção entre "explicação" e "compreensão" é a tentativa de definição para manter duas questões separadas, explica Danner (2006), pois, coloquialmente a palavra "compreender" tem muitas operações. "compreensão" e "explicação", no sentido hermenêutico, são termos técnicos.

Explicações (Erklären), nesse sentido técnico, são o que as ciências naturais fornecem em suas respostas às perguntas da forma "por que ocorreu $x$ ?", em que $x$ é um fenômeno natural. Nesse sentido técnico, as explicações fazem uso essencial das leis naturais. A compreensão (Verstehen), no sentido técnico, é fornecida pelas ciências sociais e humanas em resposta a alguém que "não está entendendo $y^{\prime \prime}$, em que $y$ é algo de origem enfaticamente humana, como um conceito, um texto literário ou filosófico, uma obra de arte, um indivíduo ou uma ação coletiva, uma instituição, um processo histórico que envolve ação humana e coisas do gênero. A compreensão, em seu sentido técnico, refere-se essencialmente a uma dimensão "interna" de certos fenômenos que são indiscutivelmente parte da esfera humana. Compreensão tenta captar "significado", uma noção que se supõe ser inteiramente estranha ao mundo natural não humano (e constitui, se não explicada e exemplificada, um conceito bastante ambíguo e pouco claro). (HOYNINGEN-HUENE, 2013, p. 54, tradução nossa).

A literatura sobre metodologia tem colocado os termos explicação (Erklären) e compreensão (Verstehen) como opostos. Esse é um erro, pois consideram o significado coloquial das palavras. Eles não são opostos, são diferentes. E para a filosofia alemã, essas duas palavras constituem termos técnicos. Como Weber (1988) deixou claro em seus escritos sobre métodos, a compreensão do significado é um pré-requisito para a possibilidade de explicar algo.

A compreensão pode distinguir os seguintes elementos estruturais (DANNER, 
2006, p. 52):

a) nós identificamos uma coisa, uma operação verdadeira sensorial;

b) reconhecemos isto ou aquilo como algo humano;

c) nós entendemos reflexivamente a sua importância, o significado do Humano. Todo o processo em uma unidade que chamamos de compreensão.

O conceito hermenêutico de compreensão, então, está direcionado para o Humano (intelectual) especificamente sobre ações, estruturas linguísticas e entidades nãolinguísticas. Além do mais, o que foi identificado na ação sensorial seja percebido como importante, ele é refletido e, então, compreendido criando um significado.

A responsabilidade da compreensão diz respeito à subjetividade e à generalidade, ou seja, os sentidos são realmente dados a nós como indivíduos, mas histórica e sócioculturalmente condicionados, não a priori como alguns sentidos "absolutos". É a compreensão do "espírito objetivo".

A responsabilidade da compreensão hermenêutica pode ser vista entre dois extremos: entre a subjetividade (evitável), por um lado, que é determinada pela arbitrariedade aleatória e de simples auto-consciência e é vista em um nível puramente psicológico, e do outro, a generalidade, face a um ideal científico em que qualquer declaração esteja acessível em todos os momentos. Ambas as opções são regidas pela hermenêutica. (DANNER, 2006, p.60, tradução nossa).

Dessa forma, o significado é baseado na comunhão de "espírito objetivo" e subjetividade que são condicionados historica e culturalmente.

A hermenêutica ocorre no movimento do círculo hermenêutico entre objetividade e subjetividade em que o aumento da compreensão consiste na realização progressiva de um etapa. Este movimento de compreensão é chamado círculo hermenêutico. Do ponto de vista da abordagem metódica, é importante manter a estrutura circular em mente, porque podem ser necessários tanto o lado objetivo quanto o lado subjetivo na interpretação.

As regras hermenêuticas são considerações sistemáticas dos conceitos que estão intimamente ligados: a "compreensão", o "espírito objetivo" e o "círculo hermenêutico". Elas fornecem apenas assistência ao processo de compreensão, porque elas não podem 
ser utilizadas como ferramentas metodódicas fechadas para chegar a resultados garantidos. Para tal, Danner (2006) explicita três elementos para as regras hermenêuticas:
a) interpretação preliminar;
b) interpretação de texto imanente; e
c) intepretação coordenada.

Regras hermenêuticas são destinadas essencialmente aos intérpretes para prestar assistência. Eles são dependentes particularmente da teoria hermenêutica. Por isso, a Hermenêutica não é um método de técnica, mas está em conexão com a interpretação do texto. Hermenêutica é uma habilidade que exige clareza especial da mente.

\subsection{Análise de conteúdo qualitativa}

Análise de conteúdo qualitativa é um método para descrever sistematicamente o significado dos dados qualitativos. Isto é feito através da atribuição de partes sucessivas do material para as categorias de uma estrutura de codificação. Este quadro é o cerne do método, e que contém todos os aspectos que caracterizam a descrição e interpretação do material.

Três aspectos caracterizam a análise de conteúdo qualitativa: redução de dados, sistematização e flexibilidade. 0 primeiro aspecto diz respeito à contribuição desse método com a redução dos dados da quantidade de material, porque exige do pesquisador a concentração em aspectos selecionados de significado, ou seja, aqueles aspectos que se relacionam com a questão global da investigação. Por isso, o pesquisador pode ter 100 categorias e subcategorias, no entanto as categorias são delimitadas de acordo com o que o pesquisador tem condições de manipular; sendo definido por qualquer passagem particular e levado ao mais alto nível de abstração.

A segunda característica fundamental da análise de conteúdo qualitativa é que ela é altamente sistemática, porque exige: o exame de cada parte do material, certa 
sequência de passos e a codificação. A flexibilidade é a terceira característica-chave e combina enfoques de conceito, codificação e criação de categorias. Ao mesmo tempo, uma parte das categorias devem ser sempre orientadas e certificadas por dados. Análise de conteúdo qualitativa é, portanto, flexível em que o quadro de codificação deve estar sempre encaixado no material.

Essa análise é constituida de descrição e interpretação que conduz a descrições sistemáticas, qualitativas ou quantitativas, de modo que contribui para reinterpretar as mensagens e chegar a um nível de compreensão de seus significados em um nível que vai além de uma leitura comum, explica Cohen, Manion e Morrison (2011).

A análise de conteúdo qualitativa é adequada para diversas fontes de materiais, visuais ou verbais, auto-gerados (através da realização de entrevistas ou grupos focais etc.) ou mostrados a partir de fontes disponíveis (sites, jornais, revistas, blogs, cartas, artigos, etc.). Por causa desta flexibilidade inerente, o método foi aplicado em diversas disciplinas e pesquisas em educação, psicologia, sociologia, ciência política, estudo empírico da literatura, e pesquisa em campos relacionados com a saúde. Porém, há que se pensar que análise de conteúdo qualitativa tem suas limitações, pois o foco desse método consiste apenas na descrição. No entanto, se um pesquisador estiver preocupado com a realização de uma análise crítica, uma análise do discurso, ou uma análise reflexiva, seria interessante usar método de apoio ou outro método.

\section{O USO DO MÉTODO DA ANÁLISE DE CONTEÚDO HERMENÊUTICA NA EDUCAÇÃO}

Como já dito anteriormente, o método da análise de conteúdo hermenêutica é um mixed methods e por isso alia análise de conteúdo qualitativa e hermenêutica. Para a análise de um conteúdo educacional é preciso seguir os passos da análise de conteúdo qualitativa (SCHREIER, 2014) e as regras da hermenêutica (DANNER, 2006). Nesse artigo, cito como exemplo, a análise que fiz de artigos publicados em periódicos da área de antropologia da educação. Os critérios para a seleção são:

a) constar no título do artigo Antropologia da Educação ou Antropologia e Educação, cujas palavras devem estar juntas;

@rquivo Brasileiro de Educação, Belo Horizonte, v. 6, n. 13, jan-abr, 2018. 
b) período de 1980 a 2014 (período de publicações relevantes na área);

c) artigos publicados em revistas da área de Antropologia e da área de Educação com classificação na Qualis CAPEs. Esses artigos foram coletados em periódicos online e impressos da área de Educação e Antropologia com Qualis/ Capes.

A análise de conteúdo qualitativa consiste nos seguintes passos (SCHREIER, 2014):
a) decidir sobre uma questão de pesquisa;
b) selecionar o material;
c) construir uma estrutura de codificação;
d) segmentação;
e) teste de codificação;
f) avaliar e modificar a estrutura de codificação;
g) análise principal;
h) apresentar e interpretar os achados.

Para complementar a análise de conteúdo qualitativa, Danner (2006) indica algumas regras para a compreensão de um texto educacional:

a) interpretação preliminar: considerar a edição do texto (primeira ou segunda versão), ter sua própria opinião sobre o texto e escrever sobre o sentido geral do texto (a primeira impressão);

b) interpretação de texto imanente: procurar o significado das palavras e relações gramaticais, observar a lógica do texto, observar contradições;

c) interpretação coordenada: observar o contexto do texto, observar a afirmação ou negação das hipóteses.

Vale ressaltar que essas regras não são normativas e taxativas e a compreensão do autor é que norteará os caminhos da compreensão do texto. Para aqueles que devem se interessam por trabalhos científicos, Danner (2006) salienta outras instruções para 
ajudá-lo na interpretação de um texto, por exemplo:

a) certifique-se de ler todo o texto;

b) estude o texto sentença a sentença, impressão após impressão; assim, realizar pelo menos o esclarecimento de contradições;

c) leia o texto novamente como um todo;

d) consulte literatura secundária, possivelmente, um texto semelhante pelo mesmo autor;

e) trazer algumas reflexões a partir do texto geral;

f) crie um esboço para todo o texto;

g) faça uma sinopse para cada seção, como formulação privada de esclarecimento;

h) por sua vez leia todo o texto.

Estas são apenas algumas dicas sem nenhum esquema rigoroso, explica Danner (2006). No entanto, essas instruções mostram que a análise hemenêutica não é feita a partir de uma leitura rápida. Eis o gráfico que mostra a junção de análise de conteúdo qualitativa e hermenêutica. 


\section{Figura 1 - Análise de conteúdo hermenêutica}

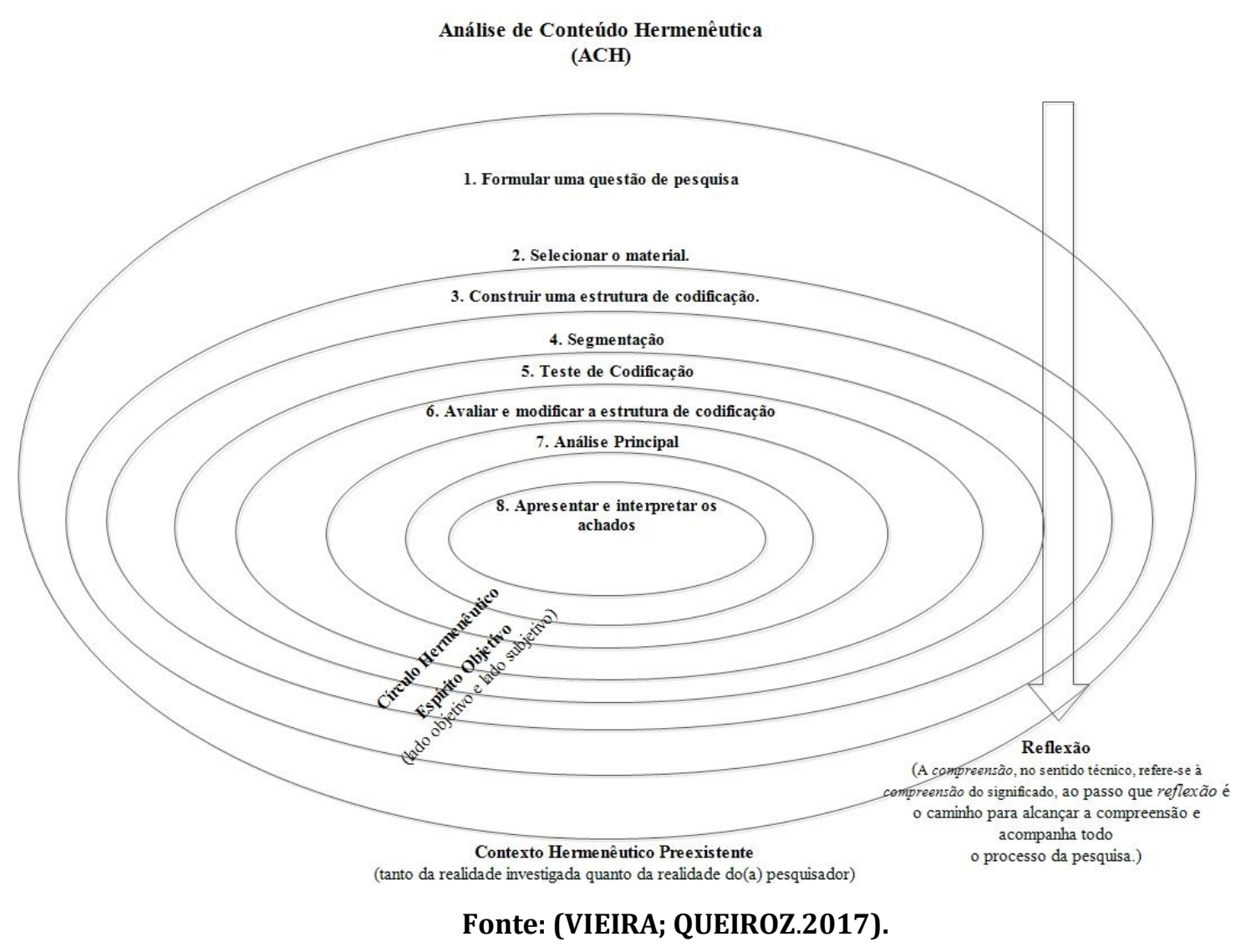

\subsection{0 passo a passo da aplicação do método na análise de artigos}

O passo a passo consiste em mostrar ao leitor como foi feita a utilização do método na área da Educação a partir dos princípios da análise de conteúdo qualitativa e da hermenêutica, contemplando a sua importância para a área da educação. Nessa pesquisa foram feitas duas análises, uma do conteúdo científico do artigo e a outra do sentido geral do texto, como será descrito a seguir.

\subsubsection{Análise do conteúdo científico do artigo}

Seguindo os passos da análise de conteúdo qualitativa em conjunto com as regras da hermenêutica ${ }^{3}$, a análise do conteúdo científico do artigo partiu de códigos pré-

\footnotetext{
${ }^{3}$ A partir dessa pesquisa, considera-se que a hermenêutica esteja implicitamente presente na análise de conteúdo qualitativa, pois a todo momento, o texto é lido sentença a sentença, relido, interpretado e analisado.
}

@rquivo Brasileiro de Educação, Belo Horizonte, v. 6, n. 13, jan-abr, 2018. 
existentes que compõem um artigo científico, por isso a análise foi guiada por elementos pré-existentes, como tema, título, autores, palavras-chave, resumo, introdução, descrição metodológica e conclusões.

Essa análise segue os seguintes passos:

1ำ passo - definição da questão da pesquisa: A análise parte do seguinte questionamento: Qual o conhecimento que tem sido construído na área de antropologia da educação no Brasil?

$2^{\text {o }}$ passo - seleção do material para a resposta do questionamento. Foram localizados 21 artigos a partir dos critérios adotados para escolha do material: artigos em cujos títulos constem antropologia da educação e antropologia e educação, cujas palavras devem estar juntas, no período de 1980 a 2014 e publicados em revistas da área de antropologia e da área de educação com classificação na Qualis CAPEs.

$3^{\text {o }}$ passo - construção da estrutura de codificação: leva em consideração os elementos estruturais de um artigo científico, como tema, título, autores (atuação, formação e temas de interesse), palavras-chave, resumo (objetivos, método e conclusão), introdução (problemática a solucionar, justificativa, estrutura teórica, objetivos e hipóteses), descrição metodológica e conclusões, ou seja, as partes que compõem um artigo científico. A estrutura de codificação já foi definida anteriormente, no sentido de validar a cientificidade dos artigos em análise.

4ํㅡㄹ passo - segmentação: nesse momento, o conteúdo do material foi dividido de acordo com as unidades de tal maneira que cada unidade se encaixa exatamente numa (sub) categoria do quadro de codificação, ou seja, aquelas apresentadas na construção da estrutura de codificação. Nesse passo da pesquisa, foram localizados e identificados ao longo dos artigos os elementos estruturais de um artigo científico. Aqui, conforme ocorria à leitura do material, o conteúdo era etiquetado com etiquetas autoadesivas de cores diferentes (uma cor para cada código), de acordo com o código pré-definido referente: tema, título, introdução, metodologia e conclusões.

5 passo - teste de Codificação: nesse momento, é realizado o teste para identificar em que momento do texto se aplica cada elemento estrutural do artigo científico. Aqui são feitas leituras e releituras do conteúdo dos artigos para testar se tal código (elementos estruturais do artigo científico) se aplica a determinado conteúdo.

@rquivo Brasileiro de Educação, Belo Horizonte, v. 6, n. 13, jan-abr, 2018. 
Como os artigos não identificavam em sua maioria a problemática e o método ficou difícil defini-los. Foram necessárias leituras e releituras, seguindo os princípios da hermenêutica de estudo de sentença a sentença e revisão dos dados.

Por exemplo, o artigo de código 21 (TOSTA, 2013) consta o método de reflexão epistemológica em perspectiva comparada da antropologia da educação do Brasil e da Argentina e o artigo de código 15 (GUSMÃO, 2009) apresenta a técnica de mapeamento dos GTs da ABA. Isso não é uma definição clara de método.

6ํㅡㄹ passo - avaliação e modificação da estrutura de codificação: envolvem a análise dos resultados da codificação em julgamento em termos de consistência e validade. Esse momento é importante, pois como na fase anterior a codificação esteve prejudicada pela falta de dados, aqui foi o momento de checar e validar a codificação. É feita releitura do conteúdo do artigo com os códigos já aplicados e se faz as modificações necessárias, caso tal código não se aplique àquele trecho do conteúdo do artigo.

Por exemplo, confirmar se o trecho "[...] definição da ciência antropológica e do conceito de cultura [...]” (TOSTA, 2011, p. 235) se encaixa no código estrutura teórica, porque não há menção de qual abordagem teórica é utilizada no texto.

7ํㅜ passo - análise principal: esse é o passo, no qual os resultados de codificação devem ser preparados de modo que eles sejam apropriados para responder à questão de pesquisa. Logo, é o momento que já é possível responder sobre a construção do conhecimento em antropologia da educação no Brasil. No sétimo passo, os trechos codificados foram realocados para um arquivo do Word em separado e cada trecho foi reorganizado em arquivos diferenciados correspondente ao código para a análise principal. Assim, seguir para o último passo que consiste em apresentar os achados e resultados e, principalmente, responder ao questionamento principal da pesquisa.

$8^{\circ}$ passo - apresentar e interpretar os achados. Esse passo envolve a apresentação do quadro de codificação com citações. Isto pode ser feito por meio de texto contínuo ou por meio de matrizes de texto, que são tabelas que contêm o texto, ou em adição aos números. Os resultados também podem servir como um ponto de partida para uma maior exploração de dados, análise dos resultados da análise de conteúdo qualitativo para padrões e ocorrências de categorias selecionadas, afirma Schreier (2014). Isso envolve ir além das unidades individuais de codificação e categorias para as

@rquivo Brasileiro de Educação, Belo Horizonte, v. 6, n. 13, jan-abr, 2018. 
relações entre as categorias.

Por exemplo, na introdução é o momento para se encontrar a problemática a solucionar, a justificativa, a estrutura teórica, os objetivos e as hipóteses. Os artigos em grande maioria não apresentavam a problemática. E na descrição metodológica, não foi possível localizar os métodos, pois em sua maioria os textos são teóricos e revisão bibliográfica.

\footnotetext{
A metodologia dos artigos de códigos 9,11,14, 15,18 e 20 não está evidente. Embora o artigo de código 14 indiquem indícios de relato de experiência, e os artigos de código 15 e 18 indiquem levantamentos. 0 artigo de código 21 explicita a metodologia. Apresentando uma abordagem qualitativa com reflexão epistemológica comparada (VIEIRA, 2017a, p. 124).
}

Desse modo, na análise dos elementos estruturais do artigo científico, então, foram identificadas quatro categorias em relação à antropologia da educação e antropologia e educação. Em relação à antropologia da educação, são: proposta para uma antropologia da educação e o método como elemento da antropologia da educação. E em relação à antropologia e educação, são: diálogo/ interface entre antropologia $e$ educação e a as contribuições da antropologia para o campo da educação.

\subsubsection{Análise do sentido geral do texto}

Como essa pesquisa foi subsidiada pela abordagem teórica e método alemão, viuse a necessidade de realizar outra análise, a análise do sentido geral do texto, porque uma análise mais aberta do conteúdo, sem interferências de pré-codificação, traria mais significado para a área em questão. Nesse sentido, a Hermenêutica foi de extrema importância no sentido de guiar a análise em seu movimento circular, aliando o lado objetivo e subjetivo da pesquisa, de modo a considerar a interpretação, a compreensão e a reflexão (VIEIRA; QUEIROZ, 2017). Essa análise também seguiu os passos da análise de conteúdo qualitativa e as regras da hermenêutica, mas não se utilizou de códigos préexistentes. Esses códigos foram criados no decorrer da leitura, releitura e análise do conteúdo.

Vejamos os passos da análise de conteúdo qualitativa em conjunto com a hermenêutica:

@rquivo Brasileiro de Educação, Belo Horizonte, v. 6, n. 13, jan-abr, 2018. 
$1^{\circ}$ passo - definição da questão da pesquisa e $2^{\circ}$ passo - seleção do material são os mesmos da primeira análise.

3o passo - construção da estrutura de codificação: leva em consideração o sentido geral do texto, por isso os artigos foram lidos sem nenhuma interferência de códigos ou de abordagem teórica. Os artigos foram lidos tendo como base a própria lógica da escrita do autor. Nesse momento, a estrutura de codificação começou a ser construída. Os trechos dos artigos já apresentavam indícios da codificação a ser constituída. A ideia recorrente dos artigos, por exemplo, sobre "as contribuições da Antropologia para o campo da Educação" levou à criação do código Antropologia como base para a área da Educação (ABAE) e o uso da Etnografia no campo da Educação (UECE). Após leituras e releituras, o conteúdo foi codificado da seguinte maneira: no bloco de antropologia da educação, os trechos dos artigos foram codificados em Antropologia como embasamento teórico e metódico (ABETM), Conceituando a Educação (COE), Imagem do profissional da área de Educação (IMPE) e A escola como lócus (ECL). No bloco de antropologia e educação, os trechos dos artigos foram codificados em ABAE, UECE, NOE, IMEP e ECL. Esses códigos guiaram a sistematização, a organização e interpretação para a categorização dos artigos. Aqui entra a primeira regra da hermenêutica, a interpretação preliminar que considera o sentido geral do texto (a primeira impressão).

$4^{\circ}$ passo - segmentação: nesse momento, o conteúdo do material foi dividido de acordo com as unidades do quadro de codificação, ou seja, aquelas apresentadas na construção da estrutura de codificação. Aqui, conforme ocorria a leitura do material, o conteúdo do artigo era etiquetado com notas autoadesivas (Post-it), de acordo com o código referente: ABETM, COE, IMPE e ECL para os artigos de antropologia da educação e ABAE, UECE, NOE, IMEP e ECL para os artigos de antropologia e educação.

5o passo - teste de codificação: nesse momento, é realizado o teste para identificar em que momento do artigo aplica-se o código criado a partir da leitura do sentido geral do texto. Aqui aplicam-se algumas instruções de Danner (2006) na qual orienta para ler todo o texto sentença a sentença, ler o texto de novo como um todo e início de uma reflexão sobre o conteúdo geral.

Por exemplo, no seguinte trecho: "Este outro olhar evoca o uso da etnografia

@rquivo Brasileiro de Educação, Belo Horizonte, v. 6, n. 13, jan-abr, 2018. 
dentro do campo da educação, não para reduzi-la a uma técnica, mas tratá-la como uma opção teórico-metodológica, o que implica conceber a prática e a descrição etnográficas ancoradas nas perguntas provenientes da teoria antropológica" (VALENTE, 2003, p. 247, código 11) ficou muito difícil definir se pertencia ao código ABAE ou UECE. Por fim, decidiu-se alocá-lo de acordo com o código UECE.

6ํㅜ passo - avaliação e modificação da estrutura de codificação: é o mesmo esquema da análise anterior, pois envolvem a análise dos resultados da codificação em julgamento em termos de consistência e validade. É feita releitura do conteúdo do artigo com os códigos já aplicados e se faz as modificações necessárias, caso tal código não se aplique àquele trecho do conteúdo do artigo.

Por exemplo, na busca por encontrar trechos que contemplassem o código NOE, a citação abaixo suscitou dúvidas no momento de modificação da estrutura de codificação, sendo que até um determinado momento esteve relacionada ao código ABAE.

Pois bem, olhada desde o horizonte da antropologia, toda a educação é cultura. Toda a teoria da educação é uma dimensão parcelar de alguns sistemas motivados de símbolos e de significados de uma dada cultura, ou do lugar social de um entrecruzamento de culturas. Estas construções históricas e cotidianas da cultura são: saberes, valores, códigos e gramáticas de relacionamentos entre as diferentes categorias de atores culturais. (BRANDÃO, 2002, p. 17, código 3).

7ํo passo - análise principal: esse é o passo, no qual os resultados de codificação devem ser preparados de modo que eles sejam apropriados para responder à questão de pesquisa. Também é um passo, no qual segue a mesma lógica da análise anterior. Logo, é o momento que já é possível responder sobre a construção do conhecimento em Antropologia da Educação no Brasil. Aqui são feitas leituras e releituras, tendo como suporte a Hermenêutica e suas regras de compreensão: interpretação de texto imanente, pois procura o significado das palavras e relações gramaticais, observa a lógica do texto e observa contradições e, a interpretação coordenada, no qual observa o contexto do texto, observa a afirmação ou negação das hipóteses.

Por exemplo, os trechos indicam a antropologia como base teórica e metódica para a educação

[...] a Antropologia da Educação aqui preconizada assenta num paradigma essencialmente interpretativo, semiológico e hermenêutico, em que a

@rquivo Brasileiro de Educação, Belo Horizonte, v. 6, n. 13, jan-abr, 2018. 
etnografia; a entrevista etnográfica e etnobiográfica; as (auto)biografias; a autorreflexão; os diários e as histórias de vida são vias fundamentais para compreender os processos educativos, de enculturação, aculturação e transmissão cultural, bem como a (re) construção identitária [...] (VIEIRA, 2013, p. 112, código 7).

a importância do resgate do referencial da antropologia na abordagem de temas singulares, particularmente na educação. [...] como referência para as pesquisas educacionais de tipo etnográfico e também para as pesquisas no campo das ciências humanas. (GUSMÃO, 1997, p. 11, código 9).

Assim, seguir para o último passo que consiste em apresentar os achados e resultados e, principalmente, responder ao questionamento principal da pesquisa.

8o passo - apresentar e interpretar os achados. Após os dados serem analisados, chega o momento da sua apresentação e interpretação. Nessa análise do sentido geral dos artigos, então, são identificadas quatro categorias em relação à antropologia da educação: a antropologia como embasamento teórico e metódico, conceituando a educação, a imagem do profissional da área de educação e escola como lócus. E são identificadas cinco categorias em relação à antropologia e educação: a antropologia como base teórica para a educação, a etnografia no campo da educação, noção de educação, a imagem do educador e a escola como lócus. Esse passo é a definição final das categorias criadas a partir da codificação, segmentação, análise, interpretação e apresentação dos dados aliados aos princípios da compreensão e reflexão do círculo hermenêutico.

\section{CONCLUSÕES}

A análise de conteúdo hermenêutica contribui para a pesquisa em educação no sentido de compreender a educação contextualizada e em profundidade. Sendo assim, a pesquisa em educação considerando esse novo método, implica em considerar a complexidade das explicações, porque na análise do conteúdo, as percepções e interpretações mudam e com elas mudam-se as verdades e envolve muitos entraves. Essa forma de interpretação e de compreensão contida na proposta hermenêutica não se dá de forma simples e livre de conflitos, explica Gadamer (1998). A pesquisa em educação, então, desenvolve-se diante de dificuldades, pois toda interpretação esta a mercê de arbitrariedades, de análises precipitadas, de opiniões prévias e de conceitos 
pré-estabelecidos.

No campo da educação é preciso que o pesquisador seja receptivo e aberto ao contexto o qual busca interpretar, precisa mostrar que não é somente um observador e analisador e, desta forma, deve salientar aos demais envolvidos, o que está pretendendo conhecer, compreender e refletir.

A análise de conteúdo hermenêutica auxilia o pesquisador na transformação da sua pesquisa a partir da interpretação e compreensão de seus dados, ou seja, significa compreender para mudar. Toda pesquisa educacional precisa ser bem pensada, ou seja, precisa ser compreendida, através de uma interpretação cuidadosa, onde a educação possa ser de fato, o lugar onde o pesquisador compreenda os seus fundamentos e suas problemáticas, logo a sua formação e a sua realidade educacional.

0 trabalho do pesquisador em educação deve promover o questionamento, a crítica, a reflexão e ação do sujeito em seu mundo. As relações que se estabelecem entre os dados oportunizam os confrontos necessários para o avanço do conhecimento na área, mesmo com suas crenças, preconceitos, e ideologias, pois permite a compreensão das suas dúvidas, ou seja, a compreensão dos acontecimentos de realidade educacional. A partir desta compreensão, se propõe um novo conhecimento.

\section{REFERÊNCIAS}

ANDRÉ, Marli. O que dizem as pesquisas sobre a sala de aula do 1ํo grau? Fórum Educacional, n. 4, p. 83-91, out./dez, 1978.

BERGMAN, Manfred Max. Hermeneutic content analysis. Textual and audiovisual analysis within a mixed methods framework. In: TASHAKKORI, Abbas; TEDDLIE, Charles. Handbook of mixed methods in social \& behavioral research. London: Sage Publications, 2010. p. $379-396$.

BODGAN, Robert; BIKLEN, Sari Knopp. Qualitative research for education. Boston: Allyn e Bacon, 1982.

BRANDÃO, Carlos Rodrigues. Sobre teias e tramas de aprender e ensinar: anotações a respeito de uma antropologia da educação. Inter-ação, v. 27, n. 2, p. 1-54, maio/ago. 2002.

COHEN, Louis; MANION, Lawrence; MORRISON, Keith. Coding and content analysis. In: Research methods in education. 7. ed. London and New York: Routledge Taylor \& Francis Group, 2011. p. 559-573.

@rquivo Brasileiro de Educação, Belo Horizonte, v. 6, n. 13, jan-abr, 2018. 
DANNER, Helmut. Hermeneutik. In: DANNER, Helmut. Methoden geisteswissenschaftlicher pädagogik. einführung in hermeneutik, phänomenologie und dialektik. München: Ernst Reinhardt, GmbH \& Co KG, Verlag, München, 2006. p. 34-120.

GADAMER, Hans-George. Verdade e método: traços fundamentais de uma hermenêutica filosófica. 2. ed. Petrópolis: Editora Vozes, 1998.

GATTI, Bernadete A. Pesquisa em educação: um tema em debate. Cadernos de Pesquisa, São Paulo, n. 80, p. 106-111, fev. 1992.

GATTI, Bernadete A. Implicações e perspectivas da pesquisa educacional no Brasil contemporâneo. Cadernos de Pesquisa, São Paulo, n. 113, p. 65-81, jul. 2001.

GATTI, Bernadete A; ANDRÉ, Marli. The relevance of qualitative research methods in Education in Brazil. In: BOHNSACK, Ralf; PFAFF, Nicole; WELLER, Wivian (eds.) Qualitative analysis and documentary methods. Leverkusen Opladen: Barbara Budrich Publishers, 2010.

GUSMÃO, Neusa Maria Mendes de. Antropologia e educação: origens de um diálogo. Caderno Cedes. Campinas, v. 18, n. 43, dez. 1997.

GUSMÃO, Neusa Maria Mendes de. Entre lugares: antropologia e educação no Brasil. Educação, Santa Maria, v. 34, n. 1, p. 29-46, jan./ abr. 2009.

HOYNINGEN-HUENE, Paul. Systematicity: the nature of science. New York: Oxford University Press, 2013.

LÜDKE, Menda; ANDRÉ, Marli. Pesquisa em educação: abordagens qualitativas. São Paulo: EPU, 1986.

RITTELMEYER, Christian. Methoden hermeneutischer Forschung. In:

FRIEBERTSHÄUSER, Barbara; LANGER, Antje; PRENGEL, Annedore (orgs.) Handbuch: qualitative forschungsmethoden in der erziehungswissenchaft. Weinheim: BeltzJuventa, 2013.

RITTELMEYER, Christian; PARMENTIER, Michael. Einführung in die pädagogische Hermeneutik. Darmstadt: WBG, 2006.

SCHREIER, Margrit. Qualitative content analysis. In: FLICK, Uwe. The SAGE handbook of qualitative data analysis. Sage: Los Angeles, London, New Delhi, Singapore, Washington, 2014. p. 170-183.

TOSTA, Sandra Pereira. Antropologia e educação: interfaces em construção e as culturas na escola. Revista Inter-legere, Natal, n. 09, p. 234-252, jul./dez. 2011.

@rquivo Brasileiro de Educação, Belo Horizonte, v. 6, n. 13, jan-abr, 2018. 
TOSTA, Sandra Pereira. Cruzando fronteiras: entre a Antropologia e a educação no Brasil e na Argentina. Pro-Posições, Campinas, v. 24, n. 2, maio/ago. 2013.

VALENTE, Ana Lúcia. Antropologia e Educação: um antigo diálogo retomado? Revista da Faced, Salvador, n. 7, p. 241-259, 2003.

VIEIRA, Karina Augusta Limonta. A construção do conhecimento em antropologia da educação: levantamento, análise e reflexão de artigos publicados no Brasil. 2016. 357 f. Tese (Doutorado) - Programa de Pós Graduação em Educação Escolar, Universidade Estadual Paulista, 2016. Disponível em: http://wwws.fclar.unesp.br/agendapos/educacao_escolar/3942.pdf. Acesso em: 10 fev. 2019.

VIEIRA, Karina Augusta Limonta Análise de conteúdo hermenêutica: a aplicação do método na área da educação. In: OLIVEIRA, Sheila Fernandes Pimenta e; DAVID, Célia Maria. (Org.). Educação e desenvolvimento: prismas, movimentos e transições. Franca: Uni-FACEF; Unesp, 2017b, v. 1, p. 367-387.

VIEIRA, Karina Augusta Limonta. Antropologia da educação: levantamento, análise e reflexão no Brasil. Curitiba: CRV, 2017a.

VIEIRA, Karina Limonta; QUEIROZ, Gustavo Morais. Hermeneutic content analysis: a method of textual analysis. International Journal of Business Marketing and Management (IJBMM), v. 2, n. 8, p.08-15, 2017.

VIEIRA, Ricardo. Etnobiografias e descoberta de si: uma proposta da Antropologia da Educação para a formação de professores para a diversidade cultural. Pro-Posições, Campinas, v. 24, n. 2, p. 109-123, maio/ago. 2013.

WARDE, Mirian. 0 papel da pesquisa na pós-graduação em educação. Cadernos de Pesquisa, São Paulo, n. 73, p. 67-75, maio 1990.

WEBER, Max. Die Objektivität" sozialwissenschaftlicher und sozialpolitischer Erkenntnis. In: WEBER, Max. Gesammelte aufsätze zur wissenschaftslehre. Tübingen: Mohr-Siebeck, 1988. p. 146-214. 